\title{
Minerals and Total Polyphenolic Content of Some Vegetal Powders
}

\author{
Roxana E. TUFEANU ${ }^{1 *}$, Cecilia GEORGESCU ${ }^{1}$, Adina FRUM ${ }^{2}$, Mihaela A. TIȚA ${ }^{1}$ and Ovidiu TIȚA ${ }^{1}$ \\ ${ }^{1}$ Faculty of Agricultural Sciences, Food Industry and Environmental Protection, „Lucian Blaga” \\ University of Sibiu, Romania. \\ ${ }^{2}$ Faculty of Medicine, „Lucian Blaga” University of Sibiu, Romania \\ *Corresponding author, e-mail: elena.tufeanu@ulbsibiu.ro
}

Bulletin UASVM Animal Science and Biotechnologies 74(2)/ 2017

Print ISSN 1843-5262; Electronic ISSN 1843-536X

DOI:10.15835/buasvmcn-asb: 0002

\begin{abstract}
The total polyphenolic content and minerals were determined for chia seeds, Psyllium husks and watermelon rind powder. The minerals content was performed by using the Inductively Coupled Plasma Optical Emissions Spectrometer and Atomic Absorption Spectrometer, technique FIAS-Furnace (for Se). The sample with the highest content of polyphenols was chia (2.69 mg GAE/g s.) followed by the watermelon rind powder. Reduced amounts of polyphenols were found in the Psyllium husks. Also, the total polyphenol concentration increased with the increase of the extraction time on the ultrasonic water bath. Minerals analysis indicated that powders obtained from chia seeds and watermelon rind contained large amounts of potassium, calcium, phosphorus and magnesium. The most abundant mineral in the Psyllium husks powder was found potassium, followed by calcium. In conclusion, these powders can be used as ingredients for functional food and food supplements production due to the high nutritional content and bioactive properties.
\end{abstract}

Keywords: bioactive compounds, chia, watermelon rind, Psyllium husks

\section{INTRODUCTION}

In recent years, there has been a significant increase in the interest for bioactive compounds from plant products. Polyphenols, chemical substances found in plants, have been used in the human diet in the largest quantity (Rupasinghe et al., 2008; Saphier et al., 2017). This group of compounds are recognized for the protection against development of chronic diseases like diabetes, cancers, osteoporosis, cardiovascular and neurodegenerative diseases (Scalbert et al., 2005).

Chia seeds (Salvia hispanica L.) are used for food and medicinal purposes in Mexico since ancient times (Saphier et al., 2017). These seeds contain high amount of omega- 3 and omega- 6 fatty acids, dietary fibre and proteins (Ixtaina et al., 2011). Also these seeds have antioxidant activity due to high amount of polyphenols and tocopherols. (Capitani et al., 2012)

Psyllium is usually consumed in India and Psyllium husks are used, especially as a bulk laxative (Rao et al., 2011). Also, the demand for this product has lately increased in USA and Europe, since Psyllium soluble fibres were associated with the reducing risk of heart disease (Chugh et al., 2015; FDA, 2012).

High quantities of solid wastes are the result of the production, consumption and processing of fruits and vegetables. These agro-wastes generate pollution problems and also take place a loss of valuable nutrients and biologically active components (Morais et al., 2017). Watermelon is a sweet fruit of summer, with high moisture content (El-Badry et al., 2014; Egbuonu, 2015). The most consumed part of watermelon 
is the pulp, while the rind is considered waste. Watermelon rinds contained important amounts of citrulline, recognized for the antioxidant capacity and roles in vasodilatation (Rimando and Perkins-Veazie, 2005).

It is very important to know the nutritional and bioactive characteristics of products that can be consumed as such or used for food products or for food supplements production. The main purpose of this research was to determine the total content of polyphenols and mineral salts from four vegetal products.

\section{MATERIALS AND METHODS}

Chia seeds, Psyllium husks and watermelon fruit were purchased from local markets. Watermelon fruit was washed to remove impurities, was sliced and the rind was collected. The respective rind was milled with a knife mill Grindomix GM 200, (Retsch) and then dehydrated by two processes: oven drying and freeze-drying (lyophilisation), until the samples reached a constant mass. Then the dehydrated samples were milled again to obtain the powder, which was kept in airtight container, at room temperature, prior to use. Also, the chia seeds and Psyllium husks were milled to obtain a fine powder.

The samples were encoded as follows: chia seeds powder-C.s.p.; Psyllium husks powderP.h.p.; watermelon rind powder (oven drying)W.r.p1 and watermelon rind powder (freezedrying) - W.r.p2.

Minerals content $(\mathrm{Ca}, \mathrm{K}, \mathrm{Na}, \mathrm{Mg}, \mathrm{Mn}, \mathrm{P}, \mathrm{Zn}$, $\mathrm{Cu}, \mathrm{Fe}$ ) was determined by Inductively Coupled Plasma Optical Emissions Spectrometry and for Selenium was used Atomic Absorption Spectrometry, technique FIAS-Furnace. Microwave Reaction System SOLV-Multiwave Pro with Rotor HF 16-100 (Anton Paar) was used for the sample mineralization. Approximately 1 $\mathrm{g}$ of sample was weighed in the reaction vessels of the mineralization system. All reagents used were in analytical grade: $\mathrm{H}_{2} \mathrm{O}_{2}(30 \% ; 2 \mathrm{~mL})$, $\mathrm{HNO}_{3}(65 \%$, Merck; $11 \mathrm{~mL})$ and $\mathrm{HCl}(37 \%$ suprapur, Merk; $1 \mathrm{~mL}$ ). The multi-element standard solutions were from Perkin Elmer Inc. Appropriate dilutions of stock standards were used for the calibration curves. Minerals concentrations were measured by using ICPOES (Optima 8300 DV, Perkin Elmer) and AAS (PinAAcle 900T, Perkin Elmer) at different wavelengths using argon as carrier gas: Ca317.93; Cu-327.39; Fe-238.20; K-766.49; Mg285.21; Na-589.59; Mn-257.61; P-214.91; Zn213.85; Se-196.03 nm.

For the polyphenols extraction a solvents mixture: $\mathrm{MeOH}: \mathrm{H}_{2} \mathrm{O}: \mathrm{HCl}$ 70:29:1 (v/v/v) and different extraction times were used. $10 \mathrm{~mL}$ of solvent mixture were added to $500 \mathrm{mg}$ of vegetal sample. The extraction was performed in two cycles on an ultrasound water bath (Sonorex, Bandelin) at $40^{\circ} \mathrm{C}$. For the extraction 1 , the first step consisted of 30 minutes on the ultrasonic water bath, followed by centrifugation of the supernatant at $8000 \mathrm{rpm}$ for 10 minutes. The residue was extracted again with $10 \mathrm{~mL}$ of solvent for 10 minutes. The supernatant was evaporated to dryness with Hei-VAP Precision Rotary Evaporator (Heidolph) under reduced pressure, at $40^{\circ} \mathrm{C}$. The residue was taken in $10 \mathrm{~mL}$ of $\mathrm{MeOH}$, filtered, and then filled to $10 \mathrm{~mL}$ volume with the same solvent. For extraction 2, the first step consisted of 60 minutes on the ultrasonic water bath, followed by a second extraction of the residue for 30 minutes. The others extraction conditions were similar to those for extraction 1. The methods used for the polyphenols extraction were adapted from the method proposed by Frum (2017).

The total phenolic contents of the extracts obtained were determined by an adapted method from European Pharmacopoeia (2014), using Folin-Ciocalteu reagent. To $0.4 \mathrm{ml}$ extract were added $1 \mathrm{mLF}$ olin Ciocalteu reagent, $15 \mathrm{~mL}$ purified water and $2 \mathrm{~mL} \mathrm{Na}_{2} \mathrm{CO}_{3} 290 \mathrm{~g} / \mathrm{L}$. The mixture is maintained for 10 minutes on the ultrasonic water bath and then incubated at $40^{\circ} \mathrm{C}$ for 20 minutes. The samples thus prepared were cooled and the absorbance at $760 \mathrm{~nm}$ was measured with CECIL 1021 UV-VIS spectrophotometer. Different concentrations of gallic acid were used for the calibration curve. Results were expressed as mg gallic acid equivalents/g sample. All analyses were performed in triplicate and the mean values 
are reported.

The data were statistically analysed using the Microsoft Excel and GraphPad Prism 7.00. Tukey's multiple comparisons test and t test were carried out to detect any significant differences between the means.

\section{RESULTS AND DISCUSSIONS}

The mineral content of the analysed samples was presented in Table 1. Chia seeds powder contained large amounts of phosphorus, potassium, calcium and magnesium. Concentrations in some minerals were higher compared to the values determined by Pereira Da Silva (2016) in the chia seeds powder, grown in different areas of Brazil: Ca 430-480 mg/100 g; K 550-620 $\mathrm{mg} / 100 \mathrm{~g}, \mathrm{P} 530-640 \mathrm{mg} / 100 \mathrm{~g}$; Mg 330-350 $\mathrm{mg} / 100 \mathrm{~g}, \mathrm{Cu}$ 0.63-1.32 mg/100 g, Mn 2.48$4.05 \mathrm{mg} / 100 \mathrm{~g}$ and $\mathrm{Zn}$ 3.65-3.75 mg/100 g. For $\mathrm{Fe}$ and $\mathrm{Na}$, the values were lower compared to those presented by Pereira $\mathrm{Da}$ Silva (2016): 7.69-9.39 mg Fe/100g and 140$150 \mathrm{mg} \mathrm{Na} / 100 \mathrm{~g}$. The most abundant mineral in the Psyllium husks powder was potassium, followed by calcium, sodium, phosphorus, magnesium, iron, manganese, copper and selenium.

Regarding the mineral content of the watermelon powder obtained by two different processes (lyophilisation and oven drying), can be observed that there were no significant differences; therefore the applied methods have no important influence on the composition of the powders. Compared with other two samples, these powders have the highest potassium content. Also largest amounts of calcium, phosphorus and magnesium were found. There is a correlation with the content of Ca, Zn and P reported by El-Badry et al. (2014). For the quantities determined by $\mathrm{Cu}, \mathrm{Mn}$ and $\mathrm{Zn}$ there is correlation with the data obtained by Egbuonu (2015), and for $\mathrm{Mg}, \mathrm{Na}$ and Fe with the data presented by Morais et al. (2017). Differences may be due to the varieties and pedoclimatic conditions of the plant development.

In Figure 1, the total phenolic content (TPC) of the vegetal samples, expressed as mg gallic acid equivalents/g sample was presented. The sample with the highest content of polyphenols was chia (2.69 mg GAE/g s.). The maximum values for the total polyphenolic content of the other powders analysed were: W.r.p1-2.20 mg GAE/g s.; W.r.p2-2.13 mg GAE/g s.; P.h.p-0.75 mg GAE/g s. Also in Figure 1 can be observed that for all powders the total polyphenol concentration increased with the increase of the extraction time on the ultrasonic water bath.

The total polyphenolic content of chia seeds obtained in the present study was higher compared to the values reported by Porras-Loaiza et al. (2013), which evaluated the phenolic content of chia seeds from different locations in Mexico and reported an

Tab. 1. Mineral content of the vegetal powders

\begin{tabular}{|c|c|c|c|c|c|}
\hline \multirow{2}{*}{\multicolumn{2}{|c|}{ Minerals (mg/100 g) }} & \multicolumn{4}{|c|}{ Samples } \\
\hline & & C.s.p. & P.h.p. & W.r.p1 & W.r.p2 \\
\hline \multirow{5}{*}{ Macroelements } & $\mathrm{Ca}$ & $703.21 \pm 0.11$ & $300.38 \pm 0.51$ & $353.34 \pm 0.25$ & $372.00 \pm 0.04$ \\
\hline & $\mathbf{K}$ & $794.30 \pm 0.27$ & $1062.17 \pm 0.20$ & $2998.48 \pm 0.34$ & $3065.63 \pm 0.34$ \\
\hline & Mg & $380.49 \pm 0.34$ & $55.68 \pm 0.47$ & $181.56 \pm 0.37$ & $234.94 \pm 0.23$ \\
\hline & $\mathrm{Na}$ & $2.38 \pm 0.04$ & $88.88 \pm 0.27$ & $21.34 \pm 0.21$ & $26.17 \pm 0.20$ \\
\hline & $\mathbf{P}$ & $999.12 \pm 0.07$ & $70.32 \pm 0.18$ & $317.19 \pm 0.14$ & $328.44 \pm 0.24$ \\
\hline \multirow{5}{*}{ Microelements } & $\mathrm{Cu}$ & $1.60 \pm 0.28$ & $0.27 \pm 0.07$ & $0.43 \pm 0.07$ & $0.28 \pm 0.13$ \\
\hline & $\mathbf{F e}$ & $6.70 \pm 0.10$ & $27.71 \pm 1.03$ & $2.66 \pm 0.76$ & $3.07 \pm 0.18$ \\
\hline & Mn & $4.31 \pm 0.04$ & $1.41 \pm 0.11$ & $1.02 \pm 0.06$ & $1.42 \pm 0.38$ \\
\hline & Zn & $4.55 \pm 0.11$ & $0.78 \pm 0.42$ & $1.97 \pm 0.34$ & $1.34 \pm 0.08$ \\
\hline & Se & $0.0579 \pm 0.0008$ & $0.0147 \pm 0.0011$ & $0.0030 \pm 0.0007$ & $0.0041 \pm 0.0021$ \\
\hline
\end{tabular}

The values are expressed as means \pm standard deviation 


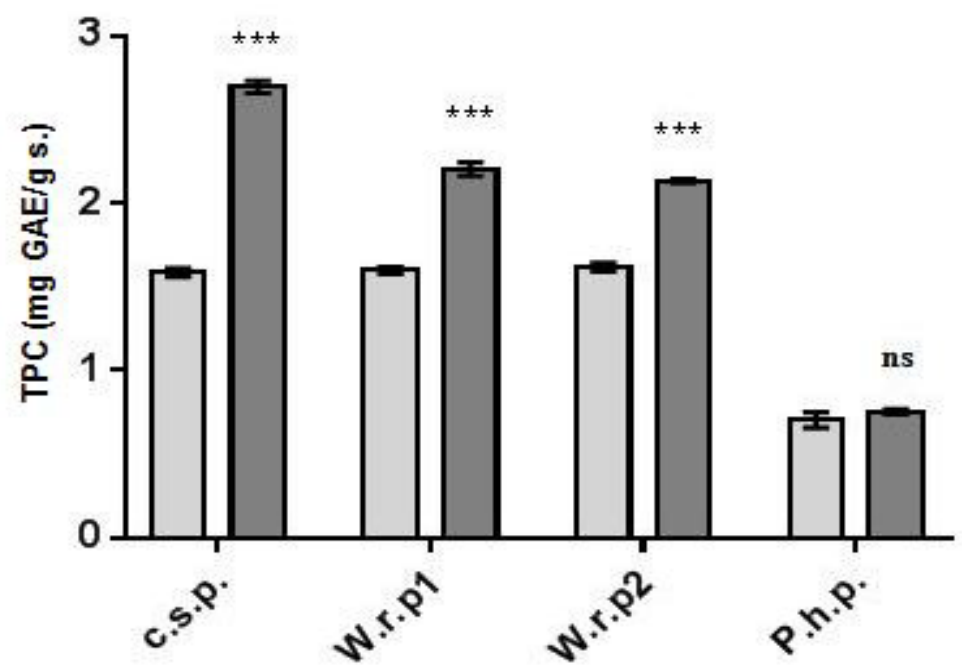

\section{$\square$ Extraction 1 \\ $\square$ Extraction 2}

Fig. 1. Total phenolic content of the vegetal samples and statistical differences between the two methods through the student test ns - $p>0,05 ; *^{*}-p<0,05$; $^{* *}$ - $p<0,01 ;{ }^{* * *}$ - $p<0,001$; Average \pm standard deviation

average of 0.9 , respectively $0.66 \mathrm{mg} \mathrm{GAE} / \mathrm{g}$. The value obtained by extraction 2 is higher than those reported by Saphier et al. (2017): $1.99 \mathrm{mg} \mathrm{GAE} / \mathrm{g} \mathrm{s.}$., Yi Ding et al. (2017): 2.39 mg GAE/g s. and Martínez-Cruz and ParedesLópez (2014): $1.64 \mathrm{mg}$ GAE/g sample. The total content of polyphenols of the watermelon rind powders was higher compared to the values reported by Ibrahim et al. (2015): 1.11 mg EAG / g s.

Significant differences were determined for the TPC of Psyllium husks powder compared to the other samples by both extraction methods. By comparing TPC values for watermelon rind and chia seeds powder, significant differences were determined through extraction 2 . These differences are mainly due to the varied phenolic compounds of the vegetal powders.

\section{CONCLUSIONS}

High amounts of phosphorus, potassium, calcium and magnesium were found in the powders obtained from chia seeds and watermelon rind. In the Psyllium husks powder potassium was found to be the most abundant mineral. Compared with the other two samples, watermelon rind powders have the highest potassium content. Also minerals such as selenium, iron, manganese, copper, zinc were found in considerable quantities in the analysed vegetal powders.

The highest content of polyphenols was found in chia seeds powder $(2.69 \mathrm{mg} \mathrm{GAE} / \mathrm{g}$

Tab. 2. Statistical differences between the four samples through the Tukey test

\begin{tabular}{|c|c|c|c|c|c|c|c|}
\hline & $\begin{array}{l}\text { Tukey's multiple } \\
\text { comparasions test }\end{array}$ & $\begin{array}{l}\text { C.s.p vs. } \\
\text { W.r.p1 }\end{array}$ & $\begin{array}{l}\text { C.s.p vs. } \\
\text { W.r.p2 }\end{array}$ & $\begin{array}{l}\text { C.s.p vs. } \\
\text { P.h.p. }\end{array}$ & $\begin{array}{l}\text { W.r.p1 vs. } \\
\text { W.r.p2 }\end{array}$ & $\begin{array}{l}\text { W.r.p1 vs. } \\
\text { P.h.p }\end{array}$ & $\begin{array}{l}\text { W.r.p2 vs } \\
\text { P.h.p }\end{array}$ \\
\hline \multirow{3}{*}{1} & Mean Diff. & $-0,01$ & $-0,03$ & 0,88 & $-0,02$ & 0,89 & 0,83 \\
\hline & P value & $<0,99$ & 0,86 & $<0,001$ & 0,99 & $<0,001$ & $<0,001$ \\
\hline & Significant & $\mathrm{ns}$ & $\mathrm{ns}$ & $* * *$ & ns & $* * *$ & $* * *$ \\
\hline \multirow{3}{*}{2} & Mean Diff. & 0,49 & 0,56 & 1,94 & 0,07 & 1,45 & 1,38 \\
\hline & P value & $<0,001$ & $<0,001$ & $<0,001$ & 0,19 & $<0,001$ & $<0,001$ \\
\hline & Significant & $* * *$ & $* * *$ & $* * *$ & ns & $* * *$ & $* * *$ \\
\hline
\end{tabular}

ns - p >0,05; ${ }^{*}-p<0,05 ; * *-p<0,01 ; * * *-p<0,001$ 
s.) followed by the watermelon rind powders dehydrated by oven drying and by lyophilisation (2.20, respectively $2.13 \mathrm{mg}$ GAE/g s.). Reduced amounts of polyphenols are found in the Psyllium husks $(0.75 \mathrm{mg}$ GAE/g s.). By using different extraction periods on the ultrasonic water bath, it was found that the total polyphenol concentration increased with the increase of the extraction time.

The applied methods for the obtaining of watermelon rind powder (lyophilisation and oven drying) had no important influence on the composition of the powders, because no major differences have been found in the total polyphenol content, respectively minerals concentrations. Due to the reduced costs, oven drying can be an efficient method, in order to exploit the bioactive and nutritive potential of a by-product compared to freeze-drying.

As indicated with the results, these powders can be used as ingredients for functional food and for food supplements production due to the high nutritional content and bioactive properties.

Acknowledgements. Authors thank to SCIENTResearch Center for Instrumental Analysis, Bucharest, Romania for the facilities provided for the minerals analysis.

\section{REFERENCES}

1. Capitani MI, Spotorno V, Nolasco SM, Tomás MC (2012). Physicochemical and functional characterization of by-products from chia (Salvia hispanica L.) seeds of Argentina. Food Science and Technology, 45, 94-102.

2. Chugh B, Singh G, Kumbhar BK (2015). Studies on the Optimization and Stability of Low-Fat Biscuit Using Carbohydrate-Based Fat Replacers. International Journal of Food Properties, 18, 1446-1459.

3. Egbuonu AC (2015). Comparative Assessment of some Mineral, Amino Acid and Vitamin Compositions of Watermelon (Citrullus lanatus) Rind and Seed. Asian Journal of Biochemistry, 10 (5), p. 230-236.

4. El-Badry N, El-Waseif MA, Badr SA, Ali HE (2014). Effect of Addition Watermelon Rind Powder on the Rheological, Physiochemical and Sensory Quality Attributes of Pan Bread. Middle East Journal of Applied Sciences, 4 (4), 1051-1046.

5. European Pharmacopoeia 8. (2014). Strasbourg Cedex: The Directorate for the Quality of Medicines and HealthCare of the Council of Europe (EDQM).

6. FDA (2012). CFR - code of federal regulations title 21. http://www.accessdata.fda.gov/scripts/cdrh/cfdocs/ cfcfr/CFRSearch.cfm?fr=101.81. Accessed 5.06.2016.
7. Frum A, Georgescu C, Gligor F, Dobrea C, Tița O (2017). Identification and Quantification of Phenolic Compounds from Red Currant (Ribes rubrum L.) and Raspberries (Rubus idaeus L.). International Journal of Pharmacology, Phytochemistry and Ethnomedicine, 6, 30-37.

8. Ibrahim UK, Yusof MIS, Zamil KAA, Kamarrudin N, Maqsood-ul-Haque SNS, Rashid SRA (2015). Total Phenolic Content and Antioxidant Activity of Local Fruit Wastes in Malaysia. Advanced Materials Research, 1113, 471-476.

9. Ixtaina VY, Martínez ML, Spotorno V, Mateo CM, Maestri DM, Diehl BWK (2011). Characterization of chia seed oils obtained by pressing and solvent extraction. Journal of Food Composition and Analysis, 24(2), p. 166-174.

10. Martínez-Cruz O, Paredes-López 0 (2014). Phytochemical profile and nutraceutical potential of chia seeds (Salvia hispanica L.) by ultra high performance liquid chromatography. Journal of Chromatography A, 1346, p. 43-48.

11. Morais DR, Rotta EM, Sargi SC, Bonafe EG, Suzuki RM, Souza NE, Matsushita M, Visentainer JV (2017). Proximate Composition, Mineral Contents and Fatty Acid Composition of the Different Parts and Dried Peels of Tropical Fruits Cultivated in Brazil. Journal of the Brazilian Chemical Society, 28 (2), 308-318.

12. Pereira Da Silva B (2016). Concentration of nutrients and bioactive compounds in chia (Salvia Hispanica L.), protein quality and iron bioavailability in wistar rats. Dissertation submitted to the Federal University of Viçosa, as part of the requirements of Program in Science of Nutrition for obtaining the title of Magister Scientiae.

13. Porras-Loaiza P, Jiménez-Munguía MT, Sosa-Morales ME, Palou E, López-Malo A (2013). Physical properties, chemical characterization and fatty acid composition of Mexican chia (Salvia hispanica L.) seeds. International Journal of Food Science and Technology, 49 (2), 571577.

14. Rao MRP, Khambete MP, Lunavat HN (2011). Study of Rheological properties of Psyllium polysaccharide and its evaluation as Suspending agent, International Journal of PharmTech Research, 3 (2), 1191-1197.

15. Rimando AM, Perkins-Veazie P (2005). Determination of citrullin in watermelon rind. Journal of Chromatography, 1078, 196-200.

16. Rupasinghe HPV, Wang L, Huber GM, Pitts NL (2008). Effect of baking on dietary fibre and phenolics of muffins incorporated with apple skin powder. Food Chemistry, 107, 1217-1224.

17. Saphier O, Silberstein T, Kamer H, Ben-Abu Y, Tavor D (2017). Chia seeds are richer in polyphenols compared to flax seeds. Integrative Food, Nutrition and Metabolism, 4(3), 1-4. 
18. Scalbert A, Johnson IT, Saltmarsh M (2005). Polyphenols: antioxidants and beyond. American Journal of Clinical Nutrition, 81, 215S-217S.

19. Yi Ding, Hui-Wen Lin, Yi-Ling Lin, Deng-Jye Yang, YuShan Yu, Jr-Wei Chen, Sheng-Yao Wang, Yi-Chen Chen
(2017). Nutritional composition in the chia seed and its processing properties on restructured ham-like products. Journal of food and drug analysis -in press (accepted 27 December 2016). 